This item was submitted to Loughborough's Research Repository by the author.

Items in Figshare are protected by copyright, with all rights reserved, unless otherwise indicated.

\title{
Community-partnered procurement : a socially sensitive option
}

PLEASE CITE THE PUBLISHED VERSION

http://www.itdgpublishing.org.uk/waterlines.html

\section{PUBLISHER}

(C) Practical Action Publishing. Originally published by ITDG Publishing

LICENCE

CC BY-NC-ND 4.0

\section{REPOSITORY RECORD}

Cotton, Andrew P., and M. Sohail. 2019. "Community-partnered Procurement : A Socially Sensitive Option". figshare. https://hdl.handle.net/2134/3983. 
This item was submitted to Loughborough's Institutional Repository (https://dspace.lboro.ac.uk/) by the author and is made available under the following Creative Commons Licence conditions.

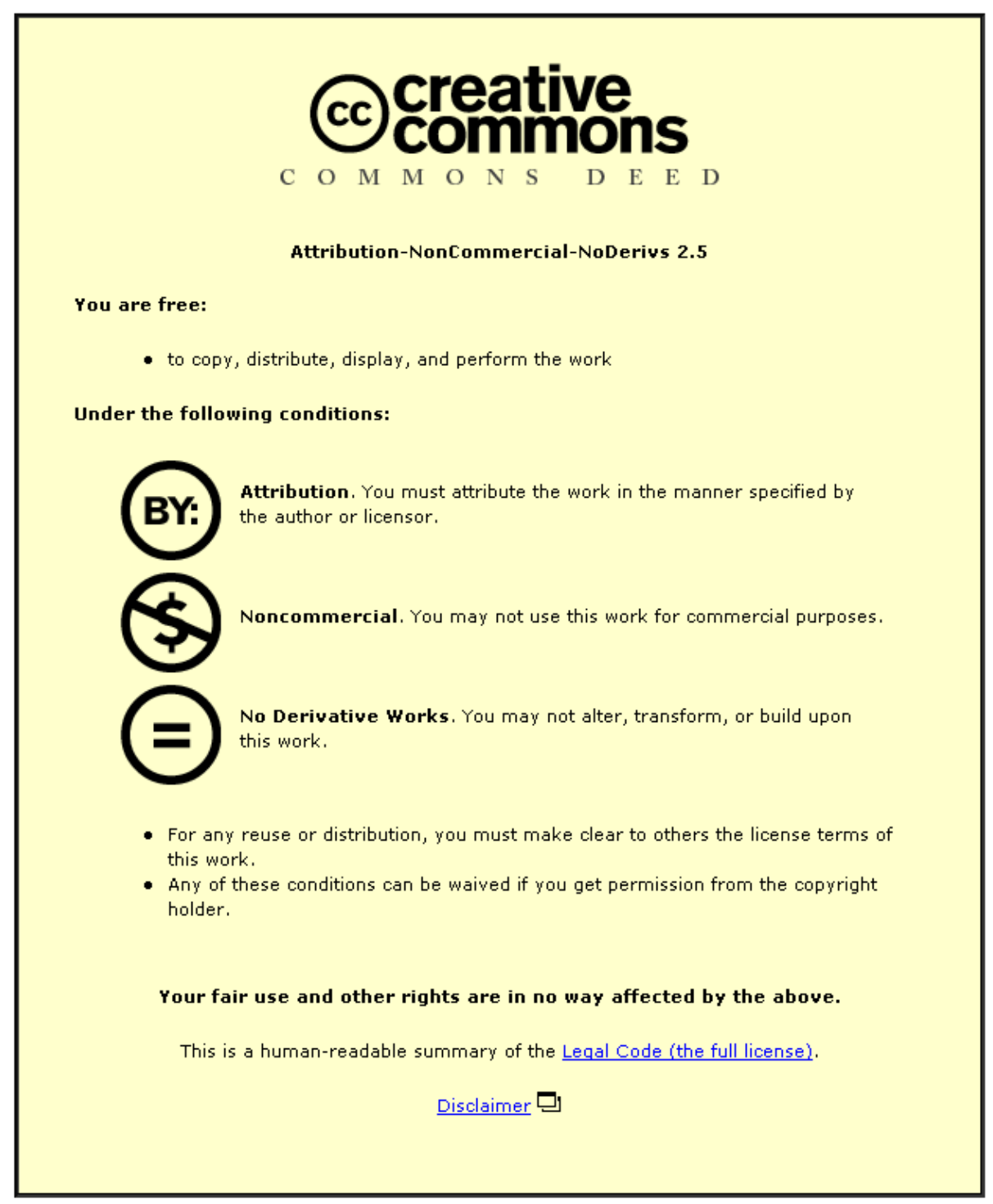

For the full text of this licence, please go to: http://creativecommons.org/licenses/by-nc-nd/2.5/ 


\section{Community Partnered Procurement- A socially sensitive option for procurement of urban infrastructure for low income communities.}

\section{Introduction}

The purpose of this paper is to provide information for promoting increased involvement of low income urban communities in the procurement of neighbourhood (tertiary level) infrastructure. The contexts are several and varied including

- upgrading works carried out by urban government

- donor funded urban development programmes

- programmes initiated by NGOs.

The paper aims to introduce the potential benefits to be gained from community partnered procurement(CPP). The content of the paper applies to those frequently occurring, low risk, routine small infrastructure works which characterise neighbourhood urban upgrading programmes and projects. We investigate cases relating to water supply, sanitation, drainage, access, paving, street and security lighting, solid waste removal, and community buildings. It is not applicable to complex, large, high risk and high hazard infrastructure projects.

The findings are based on the results of interviews and a review of literature, documents and project files on urban upgrading projects in Pakistan, India and Sri Lanka. We are particularly grateful to the many government officials who so generously gave their time to us, and provided access to very detailed information on a wide range of both community-based infrastructure works and conventional procurement contracts.

\section{Background}

The urban population in most developing countries is increasing extremely rapidly.

Conventional approaches have proved inadequate to meet the demand for shelter and services created by this rapid urban growth and this has led to a proliferation of informal, unimproved slum and squatter settlements where the inhabitants generally experience high levels of unemployment and underemployment. The United Nations Center for Human Settlements suggests that between $40 \%$ and $50 \%$ of the population in many cities live in such settlements; according to present trends, this is likely to increase.. The ability of government to provide infrastructure is already far outstripped by the inexorable increase in demand, so that the poorest and most vulnerable will continue to suffer from the lack of services and work opportunities.

This paper is about the procurement of infrastructure; that is, what mechanisms, both conventional and unconventional, government and non-government, have been adopted in efforts to deliver improved services. We explore the mechanisms and processes of agreements, procedures and contracts that are the basis for implementation of infrastructure improvements for urban low income communities. The specific focus is on situations where communities have taken a part in the planning and implementation of their neighbourhood infrastructure; this we term community partnered procurement $(C P P)$. It is clear that this approach has wider socio-economic impacts which are generally beneficial. 
There is increasing international interest in promoting the participation of community groups in improving access to basic services at the household and neighborhood levels. There is a substantial body of work addressing the issues of community participation and empowerment, which identifies barriers to increased community participation and suggests ideas and techniques for tackling the problems. These include the many currently popular tools related to PRA. Broadly speaking, this approaches matters internally, that is, the focus is on the community, although appropriate institutional responses to increase the levels of participation are also considered.

However, with regard to community partnered procurement an additional set of barriers exist, namely the rules and procedures which urban government adopts in relation to procurement. These provide the framework within which urban government operates and the key question is whether existing rules and procedures offer any scope for the increased community participation which is being advocated. We therefore look in detail at why these procedures are used and how they work; we believe that understanding these processes is central to increasing the access of community groups to the funds and other resources of urban government

There are cases where community partnered procurement operates outside the purview of urban government and we have included some examples. However, our main objective in writing this paper is to offer guidance as to how such local initiatives can be successfully integrated with urban government, as we believe that in this way it may be possible to see more responsive urban government and to increase the access which the urban poor have to resources for improved services 


\section{Infrastructure Procurement}

Procurement is the process of buying the goods, works or services, which in our case comprise the infrastructure and services described previously. In engineering terms, the works themselves are minor and usually of low cost, but are nevertheless complex to implement given the physical and social fabric of low income urban areas. We adopt the term microcontract to refer to the countless number of small contracts for works which are the mainstay of urban improvement in South Asia. The contract value is typically less than $£ 10000$. and the duration less than one year.

At this stage, it is useful to consider briefly some of the basic concepts which will be central to the analysis of our findings. The procedures refer to the organized system within which projects are conceived, planned, and brought into being by urban government. The contract is a legally binding agreement between parties based on an offer by one party to do something (in our case to construct the infrastructure) in return for a consideration (that is, payment).

In urban government in South Asia, the most commonly used procedures for the procurement of infrastructure are those which lead to the award of contracts through competitive tender. Their underlying objectives are concerned with ensuring competition which is viewed as a key factor in achieving the twin objectives of

- Accountability in the spending of public money

- Transparency in the steps of the decision-making processes

In relation to the actual contracts, we need to focus on who is involved in a contract and what their various obligations are. The most commonly used engineering contracts recognize a 'triangle of actors': Promoter; Engineer; and Contractor,

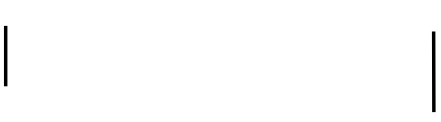

A typical case in South Asia (and elsewhere) involves urban government letting a contract to a private sector contractor for the construction of infrastructure improvements. Urban government is the promoter; they have planned and designed the work, and are paying for it to be implemented. Urban government appoints an Engineer, who is usually in the full time employment of the relevant government department. It is rare for private sector consultants to fulfill this role for minor engineering works in South Asia. In accordance with the procedures laid down a contractor is appointed to do the actual construction work.

The Engineer has the important role of ensuring that the interests of the promoter are met, and that the contractor is duly paid for his efforts. The promoter wants the best value for money and the contractor wants a good profit; whilst this can involve an enormous range of complex and contentious issues, satisfying the various interests often comes down to ensuring that a 'triangle of objectives' are met:

Cost: has the work been completed within the costs agreed in the contract?

Quality: has the work been done in accordance with what was specified ?

Time: has the work been satisfactorily completed within the time specified ?

The traditionally accepted objectives of procurement procedures and contract documents are to ensure that works are executed at the minimum cost that is consistent with the need to 
achieve a product of acceptable quality within an acceptable timeframe. They do this by reducing uncertainty, which in turn is done by:

- clearly defining who is liable to take any risk that cannot be eliminated from the project;

- providing information on the work to be carried out so that all concerned are clear about what has to be done and what their role is in doing it.

\section{Why Community Partnering ?}

Community groups and individual householders do not figure anywhere in the procedures, contracts and documentation used in these circumstances. It is assumed that they are passive consumers who are deemed to be satisfied if works are undertaken to the satisfaction of the promoter i.e. the concerned agency of urban government. However, is this assumption justified, and if not what are the implications?

Normal government practice is based on the twin assumptions that a competitive market for infrastructure provision exists and that the best way to operate in this market is through competitive tendering procedures. The competitive market only works in practice if contractors act independently; this does not always happen in practice. Certain situations exist where contractors are concerned with stability rather than expanding their market share and maximising their profitability; the outcome is that they share out the available work between them. One consequence of this 'pooling' of work is that the assumption that conventional tendering procedures will produce the lowest cost work is not justified in practice.

The role of the Engineers in urban government is to ensure that objectives relating to cost, quality and time are achieved. The objective which is most difficult to assess, and causes most concern, is the quality of the finished work. The fact is that neither they as supervisors nor the government as promoters are primary stakeholders with a strong motivation for ensuring that adequate work practices and standards are maintained.

Therefore it is questionable whether value for money is achieved; thus several reasons for promoting community partnering arise.

- Community members are directly affected by the way in which work is carried out and have a strong incentive to see that it is carried out properly.

- Resources can be channeled into the community rather being siphoned off by outside contractors. Whereas conventional procurement of infrastructure has a singe benefit, the provision of the infrastructure itself, community partnering can double the benefits obtained from investment. Infrastructure is provided and employment opportunities and enterprises are created in the community.

- People are empowered to take more control of their own lives.

- Increased access to local knowledge is gained on such issues as the location of existing service and a reduction in the potential for disputes with community members in the course of work on site.

These arguments can be opposed on a number of grounds. Many government engineers are sceptical about the ability of the community partnering to provide services to the required standard. Others fear that community partnering is likely to prove too complex to be much use in practice.

Nevertheless, we have found that the involvement of community members and groups in the procurement of their local infrastructure is quite widespread but not, at present, great in scale. Consequently there are a number of questions to be addressed

- if the procedures, contracts and documentation do not foresee a role for community members and groups, then how have existing community-based initiatives worked ? 
- to what extent do existing procedures create barriers to greater involvement of community groups as primary stakeholders ?

- how can these barriers be overcome in a way which is acceptable to urban government ?

- is there potential for increasing the scale of community partnering to a level at which it impacts on conditions in low income informal areas at a national scale? 


\section{Performance of Community Partnered Procurement}

It is necessary to review how the performance of these relatively limited experiences compares with the conventional tender contract systems. As a starting point we attempt some comparisons with the traditional performance measures of procurement contracts, namely time, cost, and quality of work. In order to achieve credibility, community partnered procurement needs to measure up at least as well as the tender contract system on these traditional performance indicators.

Cost. The use of informal negotiation to agree prices and resolve operational problems is an important feature of community partnering. However, with regard to agreeing a price, there needs to be a basis around which the negotiations can proceed. Cost estimates based on the existing Schedule of Rates has been used in Sri Lanka and India; this creates problems for community groups unless estimations based on market rates are also made. The market testing approach has also been tried.

The specific evidence we have uncovered from a preliminary analysis of individual 390 micro contracts in India and Pakistan and Sri Lanka indicates that the final price for community partnered works is lower than for the conventional tender contract system. The mean cost growth (that is, the ratio of actual completion cost to the contract cost) for 239 cases of conventionally procured works using the tender contract system is 1.0 , whereas for 151 community partnered procurement arrangements the mean value is 0.90 . The key point is that this outcome is achieved through negotiating down the rates for the work.

Time. The required completion time is specified in the conventional tender contract system; penalties such as liquidated damages can be invoked, although interviews with engineers suggest that in practice this is hardly ever done on micro contracts. The mean time growth (that is, the ratio of the actual lapse time of the construction to the duration stated in the contract) for 239 cases of conventionally procured works using the tender contract system is 1.5 , whereas for 151 community partnered procurement arrangements the mean value is 1.9. It is not clear why this is so large compared with the cost growth reported above; the implication is that cost growth is a serious concern to supervising engineers and they control it in order to avoid getting into personal difficulty. There does not seem to be a similar pressure to control time overrun. We do not yet have a similar quantitative analysis for community partnered works, but have found little concern with completion time, to the extent that it is often not mentioned at all in the agreements. In Sri Lanka, the NHDA guidelines for community based works contain a liquidated damages clause, although officials comment that they would never intend invoking it. The impression is that with community partnering arrangements there is sufficient incentive available for the work to be completed without the need for invoking penalties.

The detailed findings of the investigations into time and cost growth in micro contracts will be published separately.

Quality. It is difficult to measure quality of work in a quantitative way, and to date we have only found subjective opinions.. Supervision of work by community groups is reported to be successful. The Sri Lankan experience reports improved quality. There are no reported cases of the quality of the work being worse with community partnering. It is nevertheless important to note that some of the experiences are the outcome of an approach which has taken some considerable time and experimentation to come to fruition; the mistakes made along the way are less frequently reported. We conjecture that the time overrun described above is likely to have a deleterious effect on quality. The cost of materials rises with time (quite dramatically in some case study cities); if the total contract cost is closely controlled 
(as is the case) and material costs have risen, then it is conceivable that the contractor absorbs this by reducing the quality of work to below that specified.

Clearly, cost and quality are closely inter-related. The routine application of government procedure almost without fail selects the cheapest bid, which in certain circumstances compromises the quality of the final product.

This is symptomatic of a highly controversial argument about levels of service and design standards which has to be faced up to. Traditionally, planners and engineers develop infrastructure schemes based on predefined notions of what is best; these are reflected in the Codes of Practice and Standards which are often unrealistically high and inappropriate for the circumstances. For example in Faisalabad;Pakistan, in an upgrading programme, people want a service which is within their reach, built to standards which are appropriate for the circumstances, rather than something which somebody else has decreed is better for them. This, in fact, is no more than the sound approach which a supplier of consumer goods takes; develop products which customers want and will buy. Standards can no longer be 'absolute' and applied in a vacuum without reference to the customers.

\section{Wider Benefits of Community Partnered Procurement}

Local infrastructure improvements are usually predicated on benefits to environmental health. Our investigations lead us to believe that community partnered procurement of infrastructure may enable much wider objectives (in addition to the traditional environmental health benefits) to be achieved through addressing the poverty agenda in relation to

- the participation process as a means of offering empowerment and greater control to households and community groups;

- employment opportunities leading to income generation for low income groups who are paid for undertaking work associated with government funded infrastructure improvements;

- small enterprise development as local micro-contractors develop and exploit the niches created;

- other benefits to the local micro-economy such as increased business for building materials suppliers.

Examples included:

- In India the community started questioning and understanding the actions of the government officials as a part of empowerment.

- Money gets circulated in the local economy in cases of Pakistan.

- Opportunities of informal training for the local artisans and community members.

- Local capacity building and in some cases micro-enterprise development for example in Sri-Lanka and Pakistan.

\section{Acknowledgement.}

The authors are grateful to the Department for International Development for funding the research. The details analysis of the subject could be found in $\mathrm{PhD}$ theses(unpublished) of M.Sohail titled, 'An investigation into the procurement of urban infrastructure in developing countries' and a manual titled 'community initiatives' available from the authors at Urban Infrastructure Unit, WEDC, Loughborough University , Leicestershire, LE11 3TU. 


\section{Appendix 1}

\section{Community Partnering}

The concept of Community Partnering embraces the variety of roles and responsibilities described in Sections 2 and 3. It reflects the continued involvement of people with the planning, implementation and sustenance of local infrastructure and service improvements, and with income generation, enterprise development and skills training. This implies

- full acceptance of the urban poor as primary stakeholders in local infrastructure provision

- developing longer term more open-ended relationships, encompassing joint financing, planning, design, implementation, hand over and maintenance

- promoting co-operation both formally and informally with government agencies and NGOs

- wider targeting of the urban poor, rather than solely area-based dwellers in specific slums, as local inhabitants do not necessarily carry out improvement works themselves because of lack of both time and relevant skills. 